\title{
Soil Gas Radon Measurement for Identifying Active Faults in Thua Thien Hue (Vietnam)
}

\section{Pham Tich Xuan1, Nguyen Anh Duong², Vu Van Chinh'1, Pham Thanh Dang1, Nguyen Xuan Qua1, Nguyen Van Pho'}

\author{
${ }^{1}$ Institute of Geological Sciences, Vietnam Academy of Science and Technology, Hanoi, Vietnam \\ ${ }^{2}$ Institute of Geophysics, Vietnam Academy of Science and Technology, Hanoi, Vietnam \\ Email: xuanpt@igsvn.vast.vn, duongna@igp-vast.vn
}

How to cite this paper: Xuan, P. T., Duong, N. A., Van Chinh, V., Dang, P. T., Qua, N. X., \& Van Pho, N. (2020). Soil Gas Radon Measurement for Identifying Active Faults in Thua Thien Hue (Vietnam). Journal of Geoscience and Environment Protection, 8, 44-64. https://doi.org/10.4236/gep.2020.87003

Received: May 26, 2020

Accepted: July 17, 2020

Published: July 20, 2020

Copyright ( 2020 by author(s) and Scientific Research Publishing Inc. This work is licensed under the Creative Commons Attribution International License (CC BY 4.0).

http://creativecommons.org/licenses/by/4.0/

\begin{abstract}
The solid-state nuclear track detectors have long been applied to assess the activity of tectonic faults. We measured the Radon $\left(R_{n}\right)$ concentration in soil gas on 09 profiles with a total of 245 measurement points in Thua Thien Hue area (Vietnam). Measurement results show that the $R n$ concentration in soil gas ranges from $\sim 10 \mathrm{~Bq} / \mathrm{m}^{3}$ to $144,570 \mathrm{~Bq} / \mathrm{m}^{3}$. There is a clear difference in the $R n$ concentration on the granite rock of Dai Loc complex compared to the remaining rocks. The calculated background value and anomaly threshold of $R n$ concentration on the granite rock of Dai Loc complex and on the remaining rocks are $33,488 \mathrm{~Bq} / \mathrm{m}^{3}, 82,839 \mathrm{~Bq} / \mathrm{m}^{3}$ and $5313 \mathrm{~Bq} / \mathrm{m}^{3}, 24,850 \mathrm{~Bq} / \mathrm{m}^{3}$ respectively. Spatial distribution of $R n$ concentration in soil gas reflects the existence of faults since $R n$ concentration increases at the points above or near fault lines. The level of expression of fault activity is assessed by radon activity index $\left(K_{R n}\right)$, which is calculated by the ratio of anomaly value to background value of $R n$ concentration. According to $K_{R n}$, in Thua Thien Hue area, only the Dakrong-Hue fault shows a strong expression of activity with high and very high $K_{R n}$ (the maximum $K_{R n}=27.21$ ). The Truong Son, Huu Trach River, Ta Trach River and Bo River fault zones do not show clear activity with low and medium $K_{R n}$. There is no $R n$ anomaly value recorded on the Rao Trang fault, demonstrating that it is likely to be inactive at present. The study results indicate that the $R n$ concentration in soil gas is a strong evidence of the existence of faults or tectonic fracture zones as the $R n$ concentration always increases at the points above or near the fault line.
\end{abstract}

\section{Keywords}

Radon, Active Fault, Radon Activity Index, Thua Thien Hue, Vietnam 


\section{Introduction}

Measurement of $R n$ concentration in soil gas has long been applied to detect tectonic faults (King et al., 1996). Increasingly, this method is widely used in fault study and particularly effective in determination of active faults as well as studies on earthquake (e.g., King, 1978; Al-Hilal \& Al-Ali, 2010; Baubron et al., 2002; Font et al., 2008; Ghosh et al., 2009; González-Díez et al., 2009; Haerudin et al., 2013; Hauksson, 1981; Ioannides et al., 2003; Lombardi \& Voltattorni, 2010; Papastefanou, 2010; Richon et al., 2010; Seminsky \& Demberel, 2013; Utkin \& Yurkov, 2010; Wakita et al., 1980; Walia et al., 2008; Wang et al., 2014). The results of these studies indicate the existence of tectonic faults recorded by anomalies of $R n$ concentration. Accordingly, on fault lines or in fault zones, the $R n$ concentration in soil gas is usually high and the anomaly value often appears. This anomaly value depends on the nature, activity level and geological characteristics of the fault. However, the existence of $R n$ concentration anomalies in soil gas is not an irrefutable evidence of active fault. In order to determine the active fault through $R n$ concentration, many criteria have been used, from qualitative extrapolation to classification of $R n$ concentration anomalies into levels corresponding to activity levels of fault. One of these efforts belongs to Seminsky \& Demberel (2013). These authors proposed the radon activity index $\left(K_{Q}\right)$ which is the ratio of the maximum $R n$ concentration $\left(Q_{\max }\right)$ to the $R n$ concentration outside the fault zone. These authors also classified the radon activity index into five levels: low, medium, increased, high and ultra-high, which correspond to the activity levels of fault.

In Vietnam, the method of soil gas radon measurement has been successfully applied in determining active faults in many regions such as Northwest region, Thac Ba, Son La and Song Tranh 2 hydropower plants and proposed locations of Ninh Thuan 1 and 2 nuclear power plants in Vietnam (Tran Van Duong \& Tran Trong Hue, 1996; Tran Trong Hue, 1996, 1999; Nguyen Van Pho \& Nguyen Trong Yem, 1996; Nguyen Van Pho \& Hoang Tuyet Nga, 1996; Nguyen Van Pho et al., 1999, 2004; Pham Tich Xuan et al., 2017). Pham Tich Xuan et al. (2017) proposed calculating the radon activity index $\left(K_{R n}\right)$ based on the ratio of anomaly value of $R n$ concentration to anomaly threshold value and inherited the classification of radon activity index from Seminsky \& Demberel (2013) as mentioned above.

Thua Thien Hue province is located in Central Vietnam that possesses the complicated geological structure and is divided by tectonic faults such as Truong Son, Nam O-Nam Dong, Dakrong-Hue (Figure 1). This is the result of collision between the Indian-Australian plate and the Eurasian plate, which formed the strike-slip fault system from Myanmar to the study area in Cenozoic (Tapponnier et al., 1982; Lacassin et al., 1997; Morley, 2004; Yin, 2010; Nguyen Anh Duong et al., 2013). Although the seismic hazard is not as high as that of the countries located directly on the plate boundary such as Japan, the Philippines and Indonesia, this area is at risk of strong earthquakes with magnitude greater 
than 6 in tectonic fault zones (Nguyen Dinh Xuyen et al., 2004; Le Huy Minh et al., 2015). Therefore, the assessment of activity of tectonic fault zones is an essential task for the analysis of seismic hazard in the study area. In this study, we have determined the level of expression of fault activity by using solid-state nuclear track detector. Radon concentration is measured on 9 profiles with a total of 245 measurement points in Thua Thien Hue area. Our analysis involves newly available, unpublished $R n$ data for the study area. The activity of fault is then assessed by radon activity index $K_{R n}$. The result of activity of tectonic fault zones will be the essential information for the seismic hazard analysis in the study area.

\section{Geological Characteristics}

The study area is located in the northwest of Hue city, including some areas of A Luoi, Phong Dien, Huong Thuy, Nam Dong, Huong Tra districts and Hue city (Figure 1). This area consists of the mountainous terrain in A Luoi district with an average height of $600-800 \mathrm{~m}$ and a peak of $1774 \mathrm{~m}$, and the midland terrain including low hills and mountains with an average height of $100-200 \mathrm{~m}$ and coastal plain. According to the Geological and Mineral Resources Map (1994) of Vietnam on scale of 1:200,000 the study area is composed of Late Proterozoic-Early Paleozoic metamorphic sedimentary rocks, Paleozoic sedimentary rocks, Late Neogene-Early Quaternary terrigenous sediments and undivided Quaternary unconsolidated sediments (Figure 1). Late Proterozoic-Early Paleozoic metamorphic sedimentary rocks are composed of crystalline schists distributed in narrow strips in the southwest near the Laos border. Paleozoic sedimentary rocks occupy the majority of study area, consisting of silty sandstone, shale, andesite effusive rock, limestone and marl. Pliocene-lower Quaternary sediments are comprised of pebble, breccia, grit, sand and clay, limitedly distributed along the Ta Trach River. Undivided Quaternary unconsolidated sediments consist of pebble, breccia, sand and silt mainly distributed in the northeast along the coast and rivers.

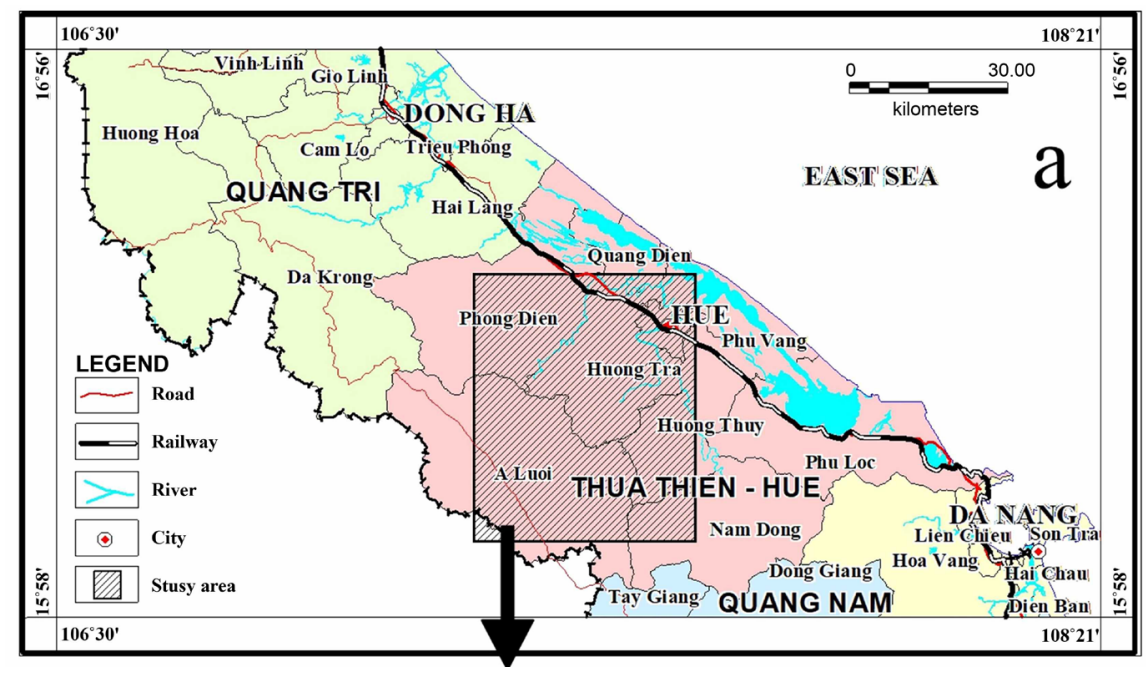




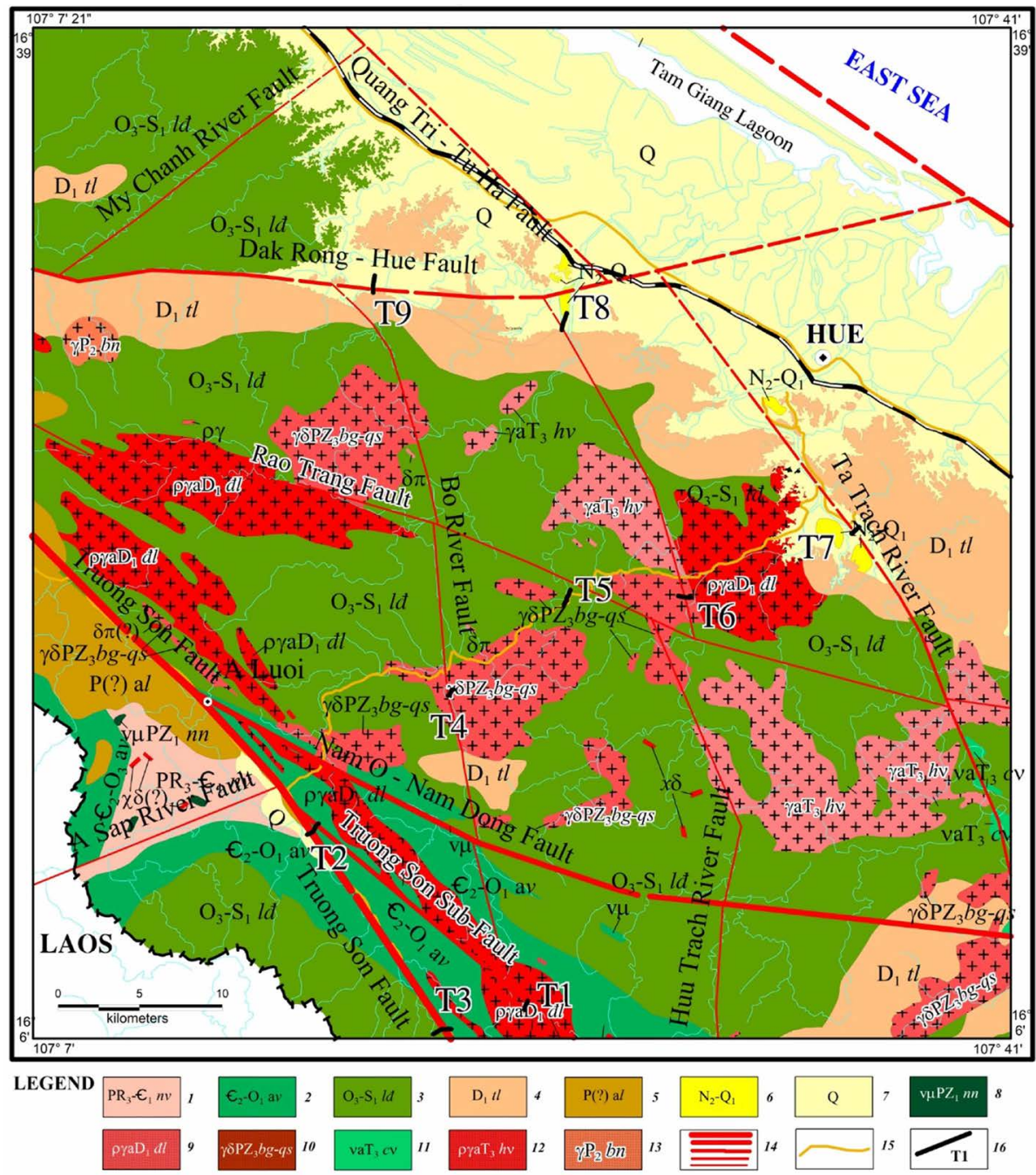

Figure 1. Location (a) and geological map of ThuaThien Hue area (After "Geological and Mineral Resources Map of Vietnam on 1:200,000 (1994)). 1. Nui Vu Formation $\left(\mathrm{PR}_{3}-\Theta_{1} \mathrm{nv}\right)$ : plagioclase-amphibole schist, actinolite-chlorite-epidote schist, quartz-mica schist, quartz-sericite schist, cherty schist; 2. A Vuong Formation $\left(\Theta_{2}-\mathrm{O}_{1}\right.$ av): sericite-quartz schist, micaceous schist, sericite-chlorite schist, interbeds of shale, greenstone lenses, quartzitic sandstone, marbleized limestone; 3. Long Dai Formation $\left(\mathrm{O}_{3}-\mathrm{S}_{1} \mathrm{ld}\right)$ : Rhythmic intercalation of quartz siltstone and sandstone, andesite interbeds, clay shale, siltstone interbeds, silty sandstone, rhythmic interbeds of chlorite-clay shale, clay shale, siltstone, interbeds of cherty clay shale, quartzitic sandstone, interbeds of clay shale, chlorite clay shale, interbeds of quartzitic sandstone, gritstone and tuff; 4 . Tan Lam Formation $\left(D_{1} t\right)$ : Limestone, marl, interbeds of clay shale; 5. A Lin Formation ( $\mathrm{P}($ ?)al): pebble-bearing gritstone, interbeds of siltstone, andesite, andesitic tuff, porphyritic dacite, siltstone, conglomerate, clayish limestone, sandstone; 6. Late Neogene-Early Quaternary sediments $\left(\mathrm{N}_{2}-\mathrm{Q}_{1}\right)$ : pebbles, breccia, grits, sand and clay; 7. Quaternary unconsolidated sediments: pebbles, brecia, sand, silt; 8. Nui Ngoc Complex ( $\left.u \mu \mathrm{PZ}_{1} \mathrm{nv}\right)$ : gabbro, gabbrodiabas; 9. Dai Loc Complex ( $\left.\rho \gamma a \mathrm{D} 1 \mathrm{dl}\right)$ : gneissogranite, granite pegmatite, granite aplite; 10 . Ben Giang-Que Son Complex $\left(\gamma \delta P Z_{3}\right.$ bg-qs): gabbrodiorite, diorite, granodiorite, horblende-biotite granite; 11 . Chaval Complex $\left(\mathrm{vaT}_{3} \mathrm{cv}\right)$ : gabbro, gabbropyroxenite; 12. Hai Van Complex ( $\rho$ aT3hv): granite, granite aplite, turmaline and garnete-bearing pegmaite; 13. Ba Na Complex ( $\gamma \mathrm{P} 2 \mathrm{bn})$ : biotite granite, two-mica granite, quartz-rich alaskite granite; 14. Tectonic Faults; 15. Roads; 16. Rn measurement profiles. 
Among magmatic rocks, the granitoid rocks predominate, including gneisogranite, granodiorite, biotite granite, two-mica granite, which are classified into Dai Loc $(\rho \gamma \mathrm{aD} 1 d l)$, Ben Giang-Que Son $\left(\gamma \delta \mathrm{PZ} \mathrm{Z}_{3} b g-q s\right)$, Hai Van $\left(\rho \gamma \mathrm{aT} \mathrm{T}_{3} \mathrm{hv}\right)$ and $\mathrm{Ba} \mathrm{Na}(\gamma \mathrm{P} 2 \mathrm{bn})$ complexes. Additionally, there also exist small gabbroic and gabbro-pyroxenitic intrusive bodies belonging to Nui Ngoc $\left(v \mu \mathrm{PZ}_{1} n v\right)$ and Cha Val $\left(v a \mathrm{~T}_{3} c v\right)$ complexes with limited outcrop area.

In the study area, tectonic faults develop in different directions, among which the northwest-southeast, sub-latitudinal and sub-longitudinal faults predominate (Figure 1). The main faults include:

The first-order Truong Son fault in this area consists of a major fault and a minor fault (Truong Son sub-fault). This fault system develops in northwest-southeast direction and runs through the southwest of study area in A Luoi district. The fault dips southeastwards with a relatively steep angle of about $70^{\circ}$ $80^{\circ}$.

The second-order Nam O-Nam Dong fault is a branch fault of Truong Son fault, which follows northwest-southeast direction in the western part and sub-latitudinal direction in the eastern part. The northwest-southeast segment (the western part) has a nearly vertical dip angle, while the sub-latitudinal segment (the eastern part) dips southwards with an angle of $70^{\circ}-80^{\circ}$.

The third-order Dakrong-Hue fault runs in the sub-latitudinal direction through Hue city and extends to the East Sea. The Dakrong-Hue fault dips towards the north-northeast with an angle of $65^{\circ}-70^{\circ}$.

The fourth-order and higher-order faults include a series of small faults such as Huu Trach River, Ta Trach River, Bo River, Rao Trang faults, etc. with different directions. The Huu Trach River fault runs along the Huu Trach River, follows northwest-southeast direction in the north from the intersection with the Dakrong-Hue fault, and changes to sub-longitudinal direction in the south (Figure 1 and Figure 2). The Ta Trach River fault runs in northwest-southeast direction, along the Ta Trach River in the northeast of study area. The Bo River fault develops in sub-longitudinal direction from the intersection with the Dakrong-Hue fault to the south and crosses other faults such as Rao Trang, Nam O-Nam Dong faults and Truong Son sub-fault. The Rao Trang fault runs in west northwest-east southeast direction through the center of study area.

\section{Data and Methodology}

The $R n$ concentration in soil gas was measured by using solid-state nuclear track detectors (SSNTDs). Film-detectors DOSIRAD LR115 (type 2P, serial number 5058180 ) with size of $1.5 \times 1.5 \mathrm{~cm}$ were used and calibrated in the standard radon chamber with known $R n$ concentration to determine detector efficiency (E) of the method. Film-detectors were glued to the bottom of plastic cups, which were then covered with thin PE film $(\sim 50 \mu \mathrm{m})$ to filter ${ }^{220} \mathrm{Rn}$ and prevent water penetration. At each measurement point, the plastic cup containing film-detector was placed face-down in the bottom of the pit of $25 \mathrm{~cm}$ diameter and $50 \mathrm{~cm}$ depth. 


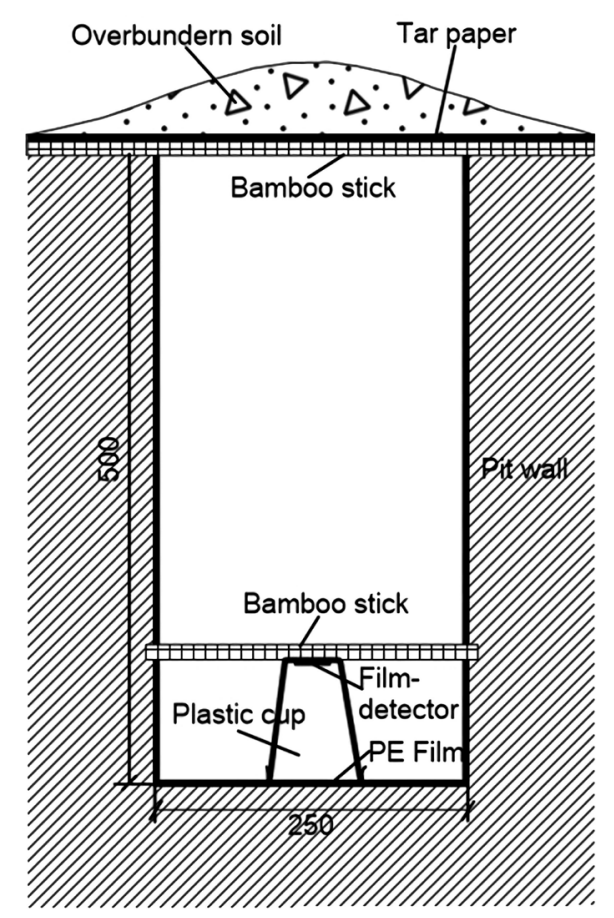

Figure 2. Setting of detector in the pit.

The pit was covered by oil-paper with supporting bamboo bars and backfilled with soil to avoid radon loss and rain (Figure 2). The average measurement time was 5 days, and the time of placing and collecting detectors was carefully recorded to the minute. The collected film-detectors were carefully preserved in plastic bags for further treatment. At each detector location, the radiation intensity in the pit bottom was measured by radiometer СРП $88 \mathrm{H}$ (Russia) to eliminate accidental accumulations near the surface of radioactive elements.

In the laboratory, film-detectors were chemically etched in $2.5 \mathrm{M} \mathrm{NaOH}$ solution for 90 minutes at a temperature of $60^{\circ} \mathrm{C}$ which was maintained constant by the thermostat HAAKE-D8. After etching, film-detectors were washed and blotted. The density of tracks was automatically counted on specialized equipment. The $R n$ concentration was calculated by using the following equation (Nidal et al., 2007):

$$
C_{R n}=\frac{D_{\mathrm{NET}}}{t \cdot E}\left(\mathrm{~Bq} \cdot \mathrm{m}^{-3}\right)
$$

where $C_{R n}-R n$ concentration in soil gas; $D_{\mathrm{NET}}$-density of tracks counted on film-detectors (track $\cdot \mathrm{cm}^{-2}$ ); $t$-time of placing detectors in the field; $E$-detector efficiency of the method. Etching, track counting and radon concentration measurement were carried out at the Institute of Nuclear Science and Technology (Hanoi).

The data were processed by statistical method; background value and anomaly threshold were determined by boxplot method (Reimann et al., 2005).

The $R n$ concentration was measured on 9 profiles with a total of 245 measurement points. The measurement profiles were determined with the help of 
geologists to ensure that they cross the fault lines. However, the actual locations of the profiles depend on specific field conditions (such as terrain, water bodies, rivers, streams, soil-rock characteristics, etc.), so most of the profiles are not straight line. The distance between detector locations was 25 - $30 \mathrm{~m}$. This distance was chosen based on the migration ability of $R n$ in soil gas (Barnet et al., 2008 ) in order that anomalies (if any) can be detected with reasonable cost. The locations of measurement points were determined by a handheld GPS device-GPSmap 60CSx. The distribution of the profiles is presented in Figure 3.

\section{Results and Discussion}

\subsection{Background Concentration and Anomaly Threshold}

Measurement results show that $R n$ concentration in soil gas ranges widely from $10 \mathrm{~Bq} / \mathrm{m}^{3}$ to $144,570 \mathrm{~Bq} / \mathrm{m}^{3}$. Some statistical parameters of $R n$ concentration are shown in Table 1 and Figure 4. The distribution of dataset of $R n$ concentration approximates to log-normal distribution.

The soil gas $R n$ concentrations on the profiles are also different. The TTH1 profile has a higher $R n$ concentration than the others in terms of the minimum, maximum and average values (Table 2 ). The $R n$ distribution and concentration

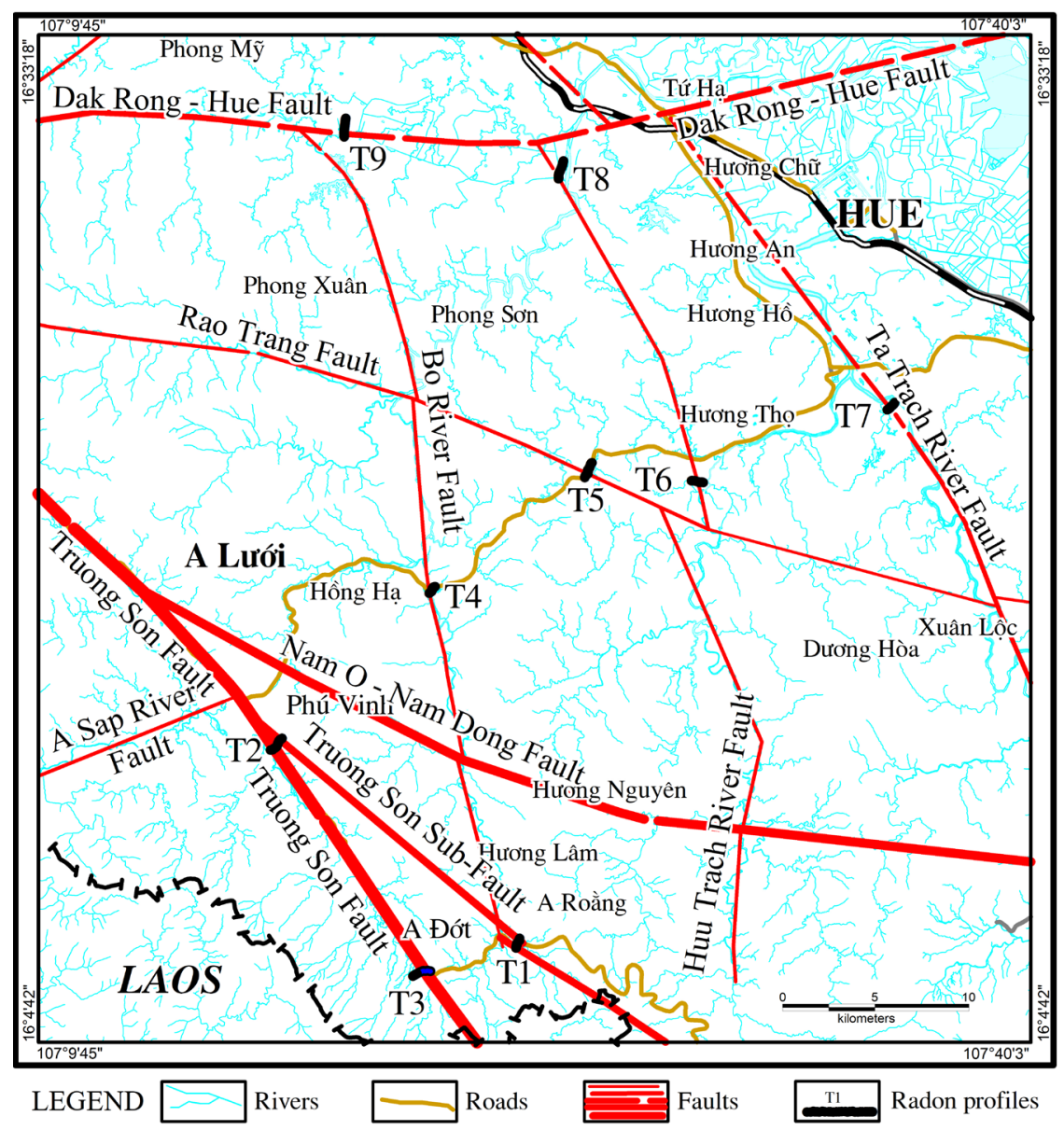

Figure 3. Distribution of soil gas radon measurement profiles in Thua Thien Hue area. 


\section{Summary: LogRn TT-Hue}
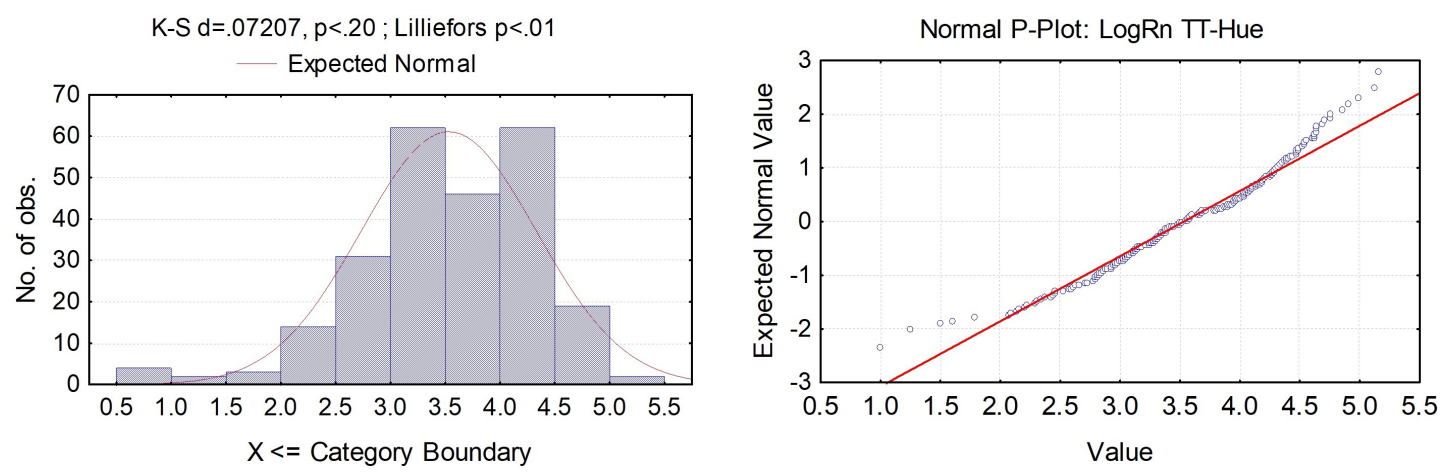

Summary Statistics:Log Rn TT-Hue

Valid N = 245; Mean = 3.53; Minimum = 1.00; Maximum = 5.16; Std.Dev. $=0.80$

Figure 4. Summary plots of log-transformed data of soil gas radon concentrations in Thua Thien Hue area.

Table 1. Statistical parameters of soil gas radon concentrations in the Thua Thien Hue area $\left(\mathrm{Bq} / \mathrm{m}^{3}\right)$.

\begin{tabular}{ccccccc}
\hline & Valid N & Median & Mean & Minimum & Maximum & Std.Dev. \\
\hline$R n$ & 245 & 3605.5 & 3388.4 & 10.0 & $144,570.0$ & $18,628.7$ \\
\hline
\end{tabular}

Table 2. Distribution of $R n$ concentration $\left(\mathrm{Bq} / \mathrm{m}^{3}\right)$ according to measurement profiles.

\begin{tabular}{cccccc}
\hline Profile & Valid N & Mean & Minimum & Maximum & Std. Dev. \\
\hline TTH1 & 23 & 37,830 & 12,460 & 133,351 & 28,284 \\
TTH2 & 30 & 9046 & 624 & 52,401 & 10,941 \\
TTH3 & 33 & 4099 & 10 & 35,085 & 7314 \\
TTH4 & 22 & 4655 & 295 & 29,479 & 7415 \\
TTH5 & 30 & 5137 & 205 & 22,042 & 6383 \\
TTH6 & 22 & 5320 & 392 & 16,532 & 4870 \\
TTH7 & 19 & 6895 & 194 & 35,849 & 9747 \\
TTH8 & 32 & 13,438 & 790 & 41,826 & 11,446 \\
TTH9 & 34 & 15,694 & 32 & 144,570 & 30,842 \\
\hline
\end{tabular}

in soil gas are influenced by physical, chemical, geological and climatic factors (Peake \& Schumann, 1993), in which the concentration of radioactive elements $\left.{ }^{238} \mathrm{U},{ }^{226} \mathrm{Ra}\right)$ and soil permeability are the most important factors. The $R n$ concentration in soil gas is usually increased along tectonic faults, probably because tectonic faults often create destructive zones increasing the soil permeability. The concentration of radioactive elements is related to the lithological properties of rock. Normally granite rocks (and also granite pegmatite) are thought to contain the higher concentration of radioactive elements compared to other rocks, therefore the soil gas $R n$ concentration in distribution area of these rocks is usually higher than in the area of other rocks. In the study area, the TTH1, 
TTH4 and TTH6 profiles are located in the outcrop area of granitoid rocks, in which the TTH1 profile is located on granitoid rocks of Dai Loc complex $\left(\rho \gamma a D_{1} d\right)$ including two-mica porphyritic gneissogranite, melanocratic gneissogranite, granite pegmatite, granite aplite, meanwhile the TTH4 and TTH6 profiles are located on granite rocks of Ben Giang-Que Son complex $\left(\gamma \delta \mathrm{PZ} \mathrm{Z}_{3} \mathrm{bg}\right.$-qs) consisting of gabbrodiorite, diorite, granodiorite, horblende-biotite granite (Figure 2). However, only the $R n$ concentration on TTH1 profile is significantly higher and different from that on TTH4, TTH6 and remaining profiles. This difference is due to lithological properties of underlying rocks. Therefore, in order to calculate thresholds of background and $R n$ concentration anomalies, the TTH1 profile needs to be examined separately to eliminate the influence of lithological factors. Although TTH4 and TTH6 routes, profiles are distributed on granite rocks, the pattern of $R n$ concentration is similar to that of other profiles, so they can be investigated together with the others.

By applying boxplot method (Reimann et al., 2005), the threshold of $R n$ background concentration was determined to be $24,850 \mathrm{~Bq} / \mathrm{m}^{3}$ for the dataset excluding TTH1 profile, meanwhile this value on TTH1 profile was $82,849 \mathrm{~Bq} / \mathrm{m}^{3}$ (Figure 5). Once the thresholds of background have been determined, all values within range of thresholds belong to the background data set, and then the $R n$ background concentration is the arithmetic mean of the whole dataset after excluding anomaly values (exceeding thresholds). Thus, in the study area two background values can be accepted, one for TTH1 profile and the other for remaining profiles. For TTH1 profile, values within range of $\leq 82,849$ belong to background dataset and the $R n$ background concentration is $33,488 \mathrm{~Bq} / \mathrm{m}^{3}$. For remaining profiles, values within range of $\leq 24,850 \mathrm{~Bq} / \mathrm{m}^{3}$ belong to background dataset and the $R n$ background concentration is $5313 \mathrm{~Bq} / \mathrm{m}^{3}$. Using the determined thresholds of $82,849 \mathrm{~Bq} / \mathrm{m}^{3}$ and $24,850 \mathrm{~Bq} / \mathrm{m}^{3}$ for $\mathrm{TTH} 1$ profile and remaining profiles respectively, 18 anomaly points of $R n$ concentration were identified (Table 3 ). It
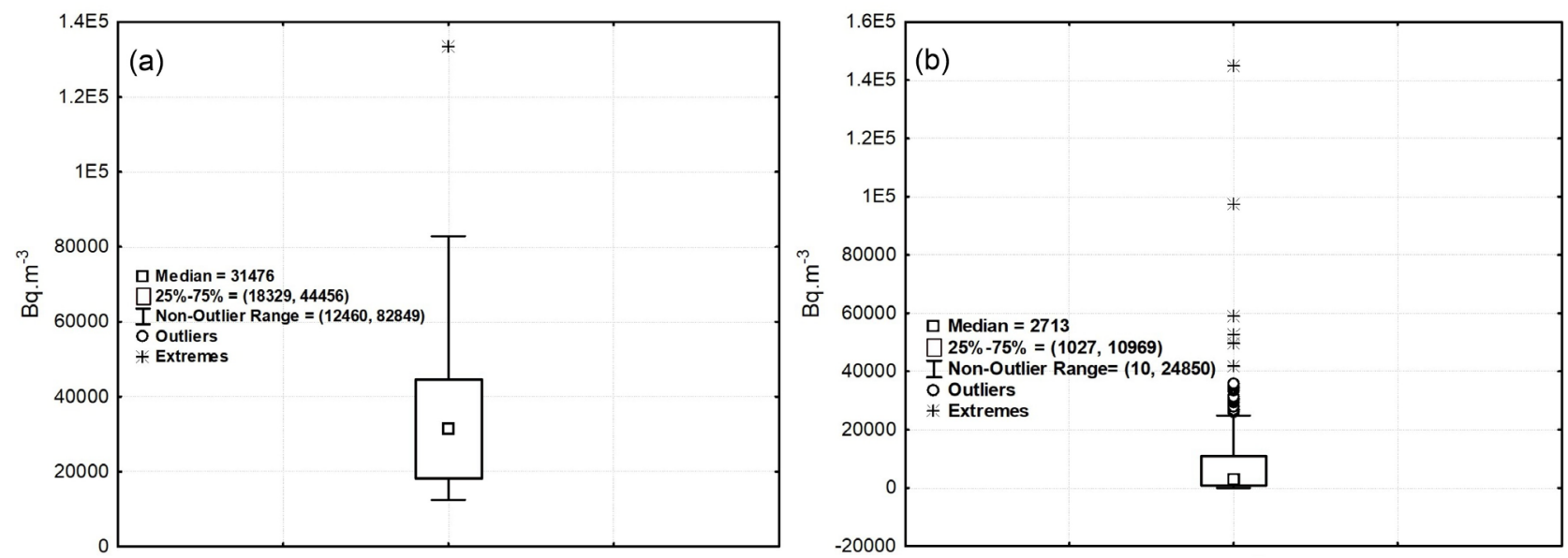

Figure 5. Soil gas radon concentration on TTH1 profile (a) and on remaining profiles (b) in Thua Thien Hue area, indicating the thresholds of $R n$ background concentration of $82,849 \mathrm{~Bq} / \mathrm{m}^{3}$ and $24,850 \mathrm{~Bq} / \mathrm{m}^{3}$ for TTH1 profile and remaining profiles respectively. 
Table 3. Anomalies of radon concentrations and Radon Activity Index $\left(K_{R n}\right)$ of Thua Thien Hue area.

\begin{tabular}{|c|c|c|c|c|}
\hline & Meas. points & Rn content $\left(\mathrm{Bq} / \mathrm{m}^{3}\right)$ & Error $\left(\mathrm{Bq} / \mathrm{m}^{3}\right)$ & $K_{R n}$ \\
\hline 1 & TTH.1-20 & 133,351 & \pm 850 & 3.98 \\
\hline 2 & TTH.9-04 & 49,557 & \pm 567 & 9.33 \\
\hline 3 & TTH.9-05 & 97,468 & \pm 795 & 18.35 \\
\hline 4 & TTH.9-06 & 144,570 & \pm 969 & 27.21 \\
\hline 5 & TTH.9-07 & 33,505 & \pm 466 & 6.31 \\
\hline 6 & TTH.9-08 & 30,592 & \pm 446 & 5.76 \\
\hline 7 & TTH.9-09 & 58,663 & \pm 617 & 11.04 \\
\hline 8 & TTH.9-17 & 26,898 & \pm 419 & 5.06 \\
\hline 9 & TTH.8-03 & 31,289 & \pm 460 & 5.89 \\
\hline 10 & TTH.8-09 & 26,067 & \pm 420 & 4.91 \\
\hline 11 & TTH.8-17 & 30,066 & \pm 452 & 5.66 \\
\hline 12 & TTH.8-22 & 27,932 & \pm 435 & 5.26 \\
\hline 13 & TTH.8-32 & 41,826 & \pm 533 & 7.87 \\
\hline 14 & TTH.2-12 & 34,291 & \pm 436 & 6.45 \\
\hline 15 & TTH.2-29 & 52,401 & \pm 540 & 9.86 \\
\hline 16 & TTH.3-26 & 35,085 & \pm 437 & 6.60 \\
\hline 17 & TTH.4-01 & 29,479 & \pm 435 & 5.55 \\
\hline 18 & TTH.7-11 & 35,849 & \pm 491 & 6.75 \\
\hline
\end{tabular}

can be seen from Table 3 that the $R n$ concentration anomalies are mostly detected on TTH9 profile (7 points) and TTH 8 profile ( 5 points). The TTH1, TTH2, TTH3, TTH4 and TTH7 profiles have 1 to 2 anomaly points, whereas no anomaly points are found on TTH5 and TTH6 profiles.

\subsection{Relationship between Radon Concentration and Activity of Fault}

The radon concentration in soil gas depends on many factors, but mainly on geological characteristics and tectonic activity of the region. Therefore, the absolute values of radon concentration in soil gas in different regions may be dissimilar or even significantly dissimilar. There are many systems for classification of radon concentrations in soil gas radon mapping. In Germany, Kemski et al. (2001) divided $R n$ concentration into 4 categories: 1$)$ low $\left.\left(<10 \mathrm{kBq} / \mathrm{m}^{3}\right), 2\right)$ me$\operatorname{dium}\left(10-100 \mathrm{kBq} / \mathrm{m}^{3}\right)$, 3) increased $\left(100-500 \mathrm{kB} / \mathrm{m}^{3}\right)$ and 4$)$ high $(>500$ $\left.\mathrm{kB} / \mathrm{m}^{3}\right)$. Meanwhile, the 3-category scale was used in Hong Kong: 1$)$ low $(<10$ $\left.\mathrm{kBq} / \mathrm{m}^{3}\right)$, 2) medium $\left(10-100 \mathrm{kBq} / \mathrm{m}^{3}\right.$ ) and 3) high $\left(>100 \mathrm{kBq} / \mathrm{m}^{3}\right.$ ) (Tung et al., 2013). The classifications of concentration levels using absolute values of soil gas $R n$ concentrations mentioned above are based on the criteria for human health and ecological environment protection and only used in soil gas radon mapping 
with the purpose of environmental protection.

Numerous studies (e.g., King et al., 1996; Moussa \& Arabi, 2003; Ciotoli et al., 1999) have shown that radon anomalous concentrations are very sensitive to fault activity. The radon anomalous concentrations in soil gas can be many times higher than the background value depending on the activity level of fault (Wang et al., 2014; Seminsky \& Demberel, 2013). Measurements of soil gas radon concentrations on several faults in different regions in the world (Richon et al., 2010) show that although the maximum $R n$ concentration and background value on different faults are very dissimilar, the ratio $K$ of the maximum $R n$ concentration to background value on the same fault or in the same measurement area is generally quite high. This indicates that active faults make the significant difference (anomalies) in radon concentration in its range of influence compared to the background concentration.

Seminsky and Demberel (2013), when studying the relationship between the $R n$ concentration in soil gas and the activity of faults in Central Mongolia, proposed using the relative index of radon activity $K_{Q}$-the ratio of the maximum $R n$ concentration $\left(Q_{\max }\right)$ to the minimum $R n$ concentration outside the fault zone $\left(Q_{\min }\right)$ for classification of fault activity. Accordingly, for Central Mongolia, the fault activity is characterized by the levels of radon activity index as follows: ultra-high $\left(K_{Q}>10\right)$, high $\left(10>K_{Q}>5\right)$, increased $\left(5>K_{Q}>3\right)$, medium ( $3>$ $\left.K_{Q}>2\right)$ and low $\left(K_{Q}<2\right)$. The use of radon activity index is, in our opinion, a more objective classification compared to the scale using absolute values. However, comparing the maximum anomaly values with the concentrations outside the fault zone by the classification scheme of Semminsky \& Demberel (2013) will lead to many uncertainties, for example which values are considered to be outside the fault zone and among these values, which ones should be chosen? Even if the location is determined to be outside the fault zone, how far is it from the fault so that the value can be chosen, etc. Therefore, the concentration comparison must be conducted based on a statistical basis, particularly comparing the concentration anomaly value with the background value. We suggested using radon activity index $K_{R n}$-the ratio of anomaly value to background value of $R n$ concentration for classification of radon activity, which corresponds to the activity level of fault.

Based on the arguments presented above, we proposed using the classification by Seminsky \& Demberel (2013) with some modifications to classify levels of radon anomalous concentration in soil gas according to radon activity index $K_{R n}$ for Thua Thien Hue area. Thus, radon activity index can be divided into 5 levels: ultrahigh $\left(K_{R n}>20\right)$, high $\left(20 \geq K_{R n}>15\right)$, increased $\left(15 \geq K_{R n}>10\right)$, medium $\left(10 \geq K_{R n}>5\right)$ and low $\left(K_{R n} \leq 5\right)$, which correspond to 5 levels of activity expression of fault (Table 4 ).

Based on this classification of activity levels of fault using radon activity index $\left(K_{R n}\right)$, Pham Tich Xuan et al. (2017) applied and satisfactorily explained the relationship between activity of fault and radon activity index in Thac Ba, Song Tranh 2 and Ninh Thuan hydropower plants (Vietnam). 
Table 4. Classification of Radon Activity Index $\left(K_{R n}\right)$ and activity expression of fault.

\begin{tabular}{ccl}
\hline \multicolumn{2}{c}{ Radon activity index } & \\
\cline { 1 - 2 }$K_{R n}$ & Level & \multicolumn{1}{c}{ Expression of fault activity } \\
\hline$K_{R n}>20$ & Ultra-high & Fault having strong activity expression \\
$20 \geq K_{R n}>15$ & High & Fault having clear activity expression \\
$15 \geq K_{R n}>10$ & Increased & $\begin{array}{l}\text { Fault having activity expression or existence of strong } \\
\text { tectonic fracture zone }\end{array}$ \\
$10 \geq K_{R n}>5$ & Medium & $\begin{array}{l}\text { Fault having not clear activity expression or existence of } \\
\text { fracture zone }\end{array}$ \\
$K_{R n} \leq 5$ & Low & Fault having no activity expression \\
\hline
\end{tabular}

Thac Ba hydropower plant is built on Chay River (Northern Vietnam), running along the northwest-southeast Chay River fault which is considered to be active in the present time with dextral strike-slip mechanism (Nguyen Trong Yem, 1996; Nguyen Dang Tuc, 2000). The distribution characteristics of radon concentration anomaly in Thac Ba hydropower plant have confirmed that (Pham Tich Xuan et al., 2017). In Thac Ba hydropower plant area, the anomalies of soil gas radon concentration range from $28,289 \mathrm{~Bq} / \mathrm{m}^{3}$ to $273,133 \mathrm{~Bq} / \mathrm{m}^{3}$ and the corresponding $K_{R n}$ values varies between 3.5 and 34.1.

Song Tranh 2 hydropower plant was built on Tranh River in Central Vietnam. Since the reservoir impoundment in early 2012, earthquakes have frequently occurred in this area. They were identified as triggered earthquakes due to impoundment (Le Huy Minh et al., 2015). The strongest earthquake with magnitude of 4.7 occurred on November 15, 2012. Soil gas radon measurement in this area showed that the maximum $R n$ concentration reached $77,729 \mathrm{~Bq} / \mathrm{m}^{3}$ and the $R n$ concentration anomalies ranged between $3974 \mathrm{~Bq} / \mathrm{m}^{3}$ and $77,729 \mathrm{~Bq} / \mathrm{m}^{3}$ corresponding to $K_{R n}$ from 1.8 to 34.9 .

The soil gas radon measurement conducted in Ninh Thuan is within the framework of studies on evaluating the proposed locations of nuclear power plants. This area is considered to be relatively stable in terms of tectonics. Geological-tectonic studies show that within the $8 \mathrm{~km}$ radius from the proposed locations of Ninh Thuan 1 and Ninh Thuan 2 nuclear power plants, there mainly exist very small tectonic fracture zones or tectonic faults which show no activity or unclear activity in the present time. The results of soil gas radon measurement indicated that the maximum $R n$ concentration reached $52,627 \mathrm{~Bq} / \mathrm{m}^{3}$, the anomalies were in the range of $15,568 \mathrm{~Bq} / \mathrm{m}^{3}$ to $52,627 \mathrm{~Bq} / \mathrm{m}^{3}$ and $K_{R n}$ varied between 3.6 and 12.1 .

The comparison between results of soil gas radon measurement in three above-mentioned areas and results of geological studies demonstrated that in Ninh Thuan area, most of anomaly points (55/57) had $K_{R n} \leq 10$, only 2 points had $K_{R n}$ of 11.3 and 12.1. It can be said that the relatively low $K_{R n}$ reflects the inactivity of faults or the anomalies in this area are only recorded in tectonic fracture zones, which increase the soil permeability, facilitating radon release, lead- 
ing to high radon concentration in soil gas. This result is completely consistent with other research results in this area. In Thac Ba area, many anomaly points had relatively high $K_{R n}(>10)$ with the maximum of 33.9, demonstrating the obvious activity of Chay River fault as recorded by previous geological studies mentioned above (Nguyen Trong Yem, 1996; Nguyen Dang Tuc, 2000). Meanwhile, in Song Tranh 2 hydropower plant, the activity of faults is clearly reflected through a series of earthquakes occurring here (Le Huy Minh et al., 2015), which was confirmed by results of soil gas radon measurement. Among a total of 115 anomaly points, the levels of $K_{R n}$ were recorded as follows: $K_{R n} \leq 5$ (3 points); $5<$ $K_{R n} \leq 10$ (57 points); $10<K_{R n} \leq 15$ (32 points); $15<K_{R n} \leq 20$ (12 points) and $K_{R n}>20$ (11 points). $K_{R n}>10$ accounted for nearly half of the anomaly points, indicating the clear activity expression of faults, in which the maximum $K_{R n}$ reached 94.2.

\subsection{Activity Expression of Faults According to the Soil Gas Measurement Data in the Thua Thien Hue Area}

As mentioned above, 18 anomaly points were determined in Thua Thien Hue area with the radon concentration ranging from $26,067 \mathrm{~Bq} / \mathrm{m}^{3}$ to $144,570 \mathrm{~Bq} / \mathrm{m}^{3}$ and the corresponding $K_{R n}$ varying between 3.98 and 27.21. The entire anomaly points with $K_{R n}>10$ are located on the Dakrong-Hue fault (on the TTH9 profile) (Table 3).

\section{+ Truong Son fault and its minor fault (Truong son sub-fault)}

The Truong Son fault is a first-order zoned fault. In the study area, it consists of a major fault and a minor fault (Figure 1 and Figure 2). On the major fault, there are two radon measurement profiles: TTH2 and TTH3, in which the TTH3 profile crosses both major and minor faults near the intersection of these two faults. On the TTH2 profile, an anomaly point TTH2-12 was recorded on the fault line with $R n$ concentration of $34,291 \mathrm{~Bq} \cdot \mathrm{m}^{-3}$ and $K_{R n}=6.45$. On the TTH3 profile crossing Truong Son fault in the south of study area, there was only one anomaly point coinciding with the fault line (TTH3-26) with $R n$ concentration of $35,085 \mathrm{~Bq} / \mathrm{m}^{3}$ and $K_{R n}=6.60$. Both anomaly points recorded on Truong Son fault have medium $K_{R n}(\leq 10)$, indicating that the activity expression of this fault is unclear in the present time, at least on A Luoi-A Dong segment (Figure 6).

There are two radon measurement profiles (TTH1 and TTH2) on the Truong Son sub-fault. On the TTH1 profile, one anomaly point which coincides with the fault line was recorded with $R n$ concentration of $133,351 \mathrm{~Bq} / \mathrm{m}^{3}$ and $K_{R n}=3.98$. On the fault line of TTH2 profile, one anomaly point (TTH2-29) was also detected with $R n$ concentration of $52,401 \mathrm{~Bq} \cdot \mathrm{m}^{-3}$ and $K_{R n}=9.86$. The combination graph of radon concentration distribution on the Truong Son sub-fault is presented in Figure 7. Among two anomaly points recorded on the Truong Son sub-fault, one has low $K_{R n}$ (on TTH1 profile) and another has medium $K_{R n}$ (on TTH2 profile), demonstrating that the activity expression of this fault is also unobvious as its major fault. 


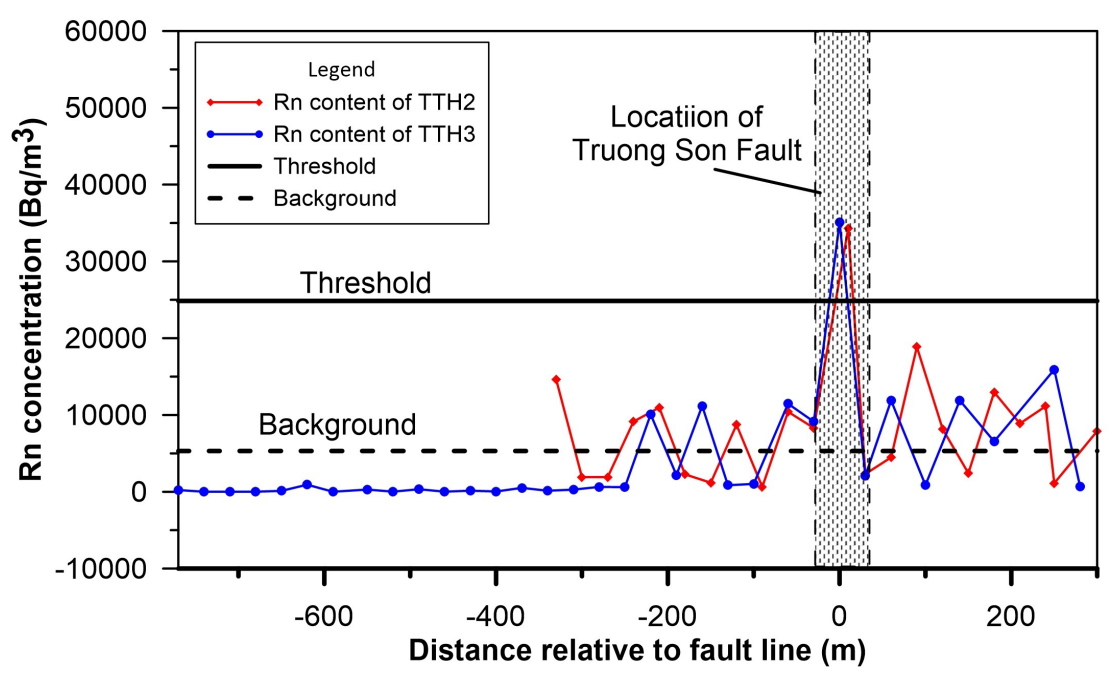

Figure 6. Combination graph of soil gas radon concentration distribution on Truong Son main fault.

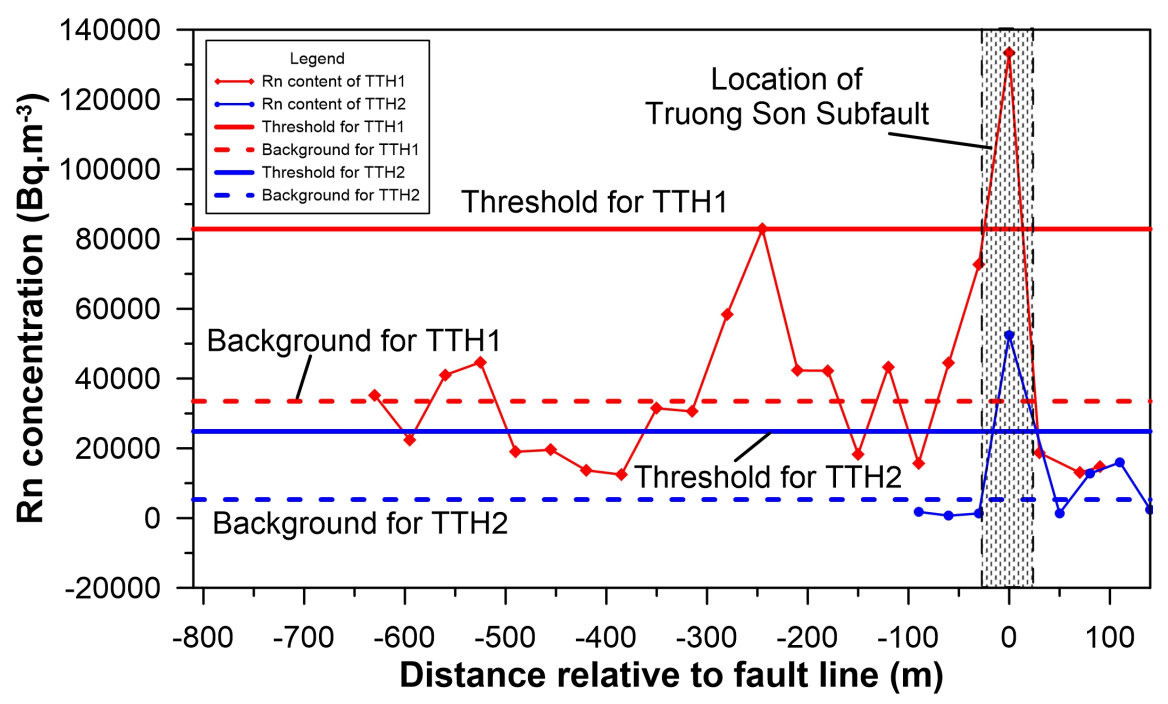

Figure 7. Combination graph of soil gas radon concentration distribution on Truong Son sub-fault.

\section{+ Dakrong-Hue fault}

On the Dakrong-Hue fault, there is only one measurement profile TTH9 located in Phong My commune (Phong Dien district). On this profile, up to 7 anomaly points were recorded, in which the anomaly points from TTH9-04 to TTH9-09 form a series of 6 continuous points with $R n$ concentration from $30,592 \mathrm{~Bq} / \mathrm{m}^{3}$ to $144,570 \mathrm{~Bq} / \mathrm{m}^{3}$, the TTH9-17 point is located further to the north with $R n$ concentration of $26,898 \mathrm{~Bq} \cdot \mathrm{m}^{-3}$. Notably, the TTH9-05 and TTH9-06 points located on the fault line have high and ultrahigh $K_{R n}$ of 18.35 and 27.21 respectively, in which the TTH9-06 point has the highest measured $R n$ concentration of $144,570 \mathrm{~Bq} / \mathrm{m}^{3}$ in the study area. The $K_{R n}$ is from high to ultrahigh, indicating that the activity expression of Dakrong-Hue fault is apparent in the present time (Figure 8). 


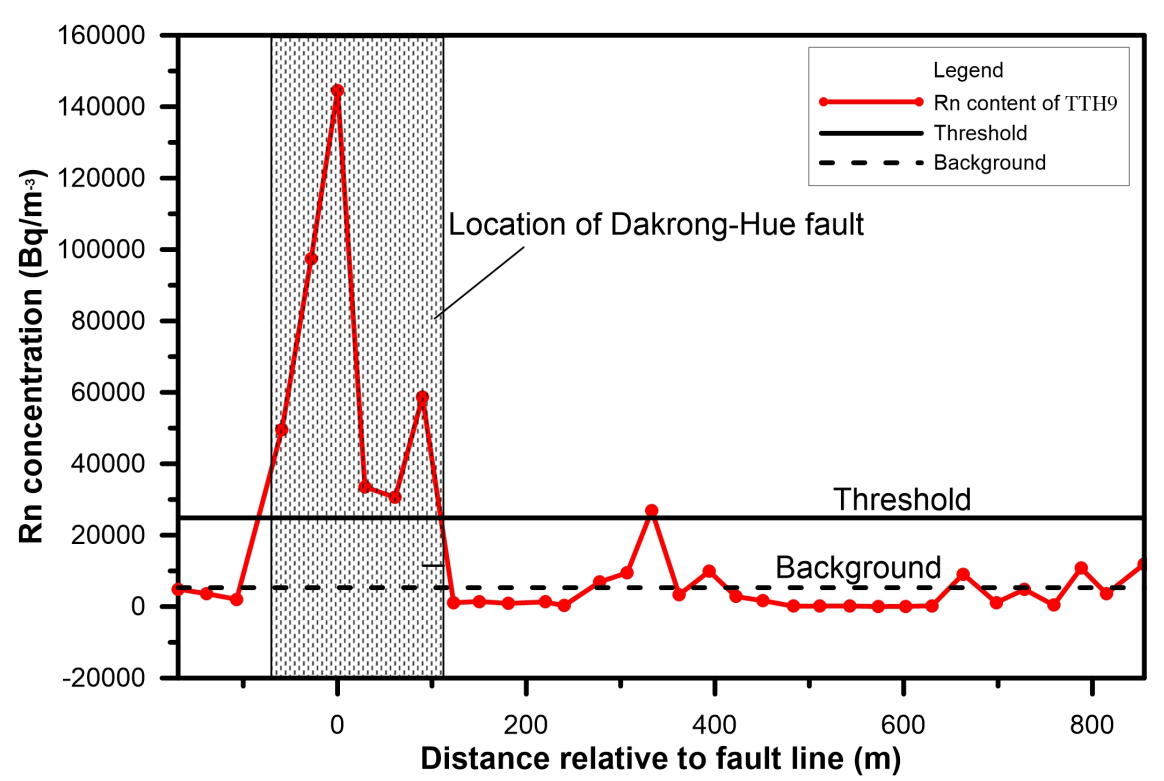

Figure 8. Distribution of soil gas radon concentration on Dakrong-Hue fault.

\section{+ Huu Trach River fault}

There are two radon measurement profiles TTH6 and TTH8 on this fault. 5 anomaly points were recorded, all of which are located on TTH8 profile. Among anomaly points, the TTH8-03 is located directly on the fault line with $R n$ concentration of $31,289 \mathrm{~Bq} / \mathrm{m}^{3}$ and $K_{R n}=5.89$. The TTH8-17, TTH8-22 and TTH8-32 points are quite far from the fault line to the north with medium $K_{R n}$ ranging from 5.26 to 7.87 (Figure 9). The $K_{R n}$ on Huu Trach River fault is at medium level, demonstrating that the activity expression of this fault is unclear. The inactivity of this fault is also manifested in the complete absence of radon concentration anomalies on the TTH6 profile which crosses the southern part of this fault. It is noteworthy that the TTH8-17, TTH8-22 and TTH8-32 points are located in the quadrant of intersection of Huu Trach River fault and Dakrong-Hue fault. The occurrence of anomaly points in this area is probably due to the extension in the quadrant caused by the movement of Dakrong-Hue fault, and these anomaly points reflect the activity of Dakrong-Hue fault rather than Huu Trach River fault.

\section{+ Ta Trach River fault}

There is one radon measurement point TTH7 on the Ta Trach River fault. On this profile, only one anomaly point located on the fault line was found with $R n$ concentration of $35,849 \mathrm{~Bq} \cdot \mathrm{m}^{-3}$ and medium $K_{R n}=6.75$. Thus, similar to the Huu Trach River fault, the activity expression of this fault is unobvious (Figure 10).

\section{+ Bo River fault}

On the Bo River fault, there is one radon measurement profile TTH4 located near the hot water source of Ngoi village in Hong Ha commune (Figure 11). Only one anomaly point (TTH4-01) was recorded at the beginning of the profile with $R n$ concentration of $29,479 \mathrm{~Bq} / \mathrm{m}^{3}$ corresponding to medium $K_{R n}=5.55$. 


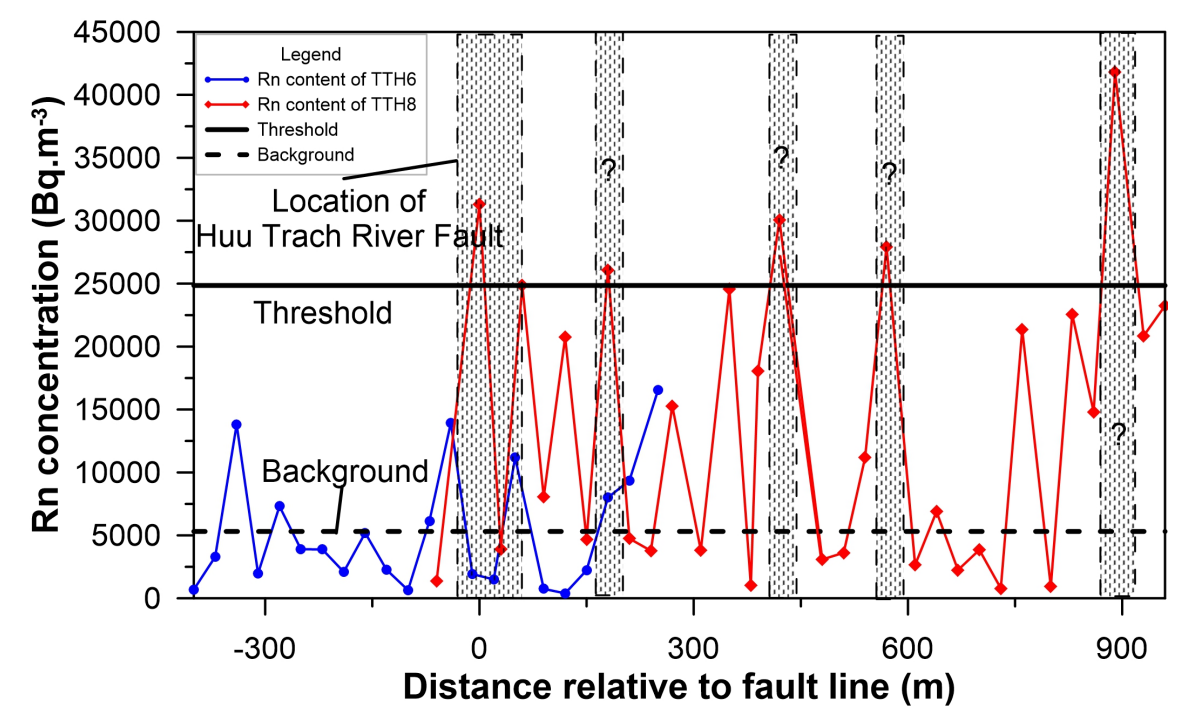

Figure 9. Combination graph of soil gas radon concentration distribution on Huu Trach River fault. In addition to anomaly on the Huu Trach River fault, there are two weak anomalies located quite far from the fault, which can result from the extension caused by movement of the Dakrong-Hue fault.

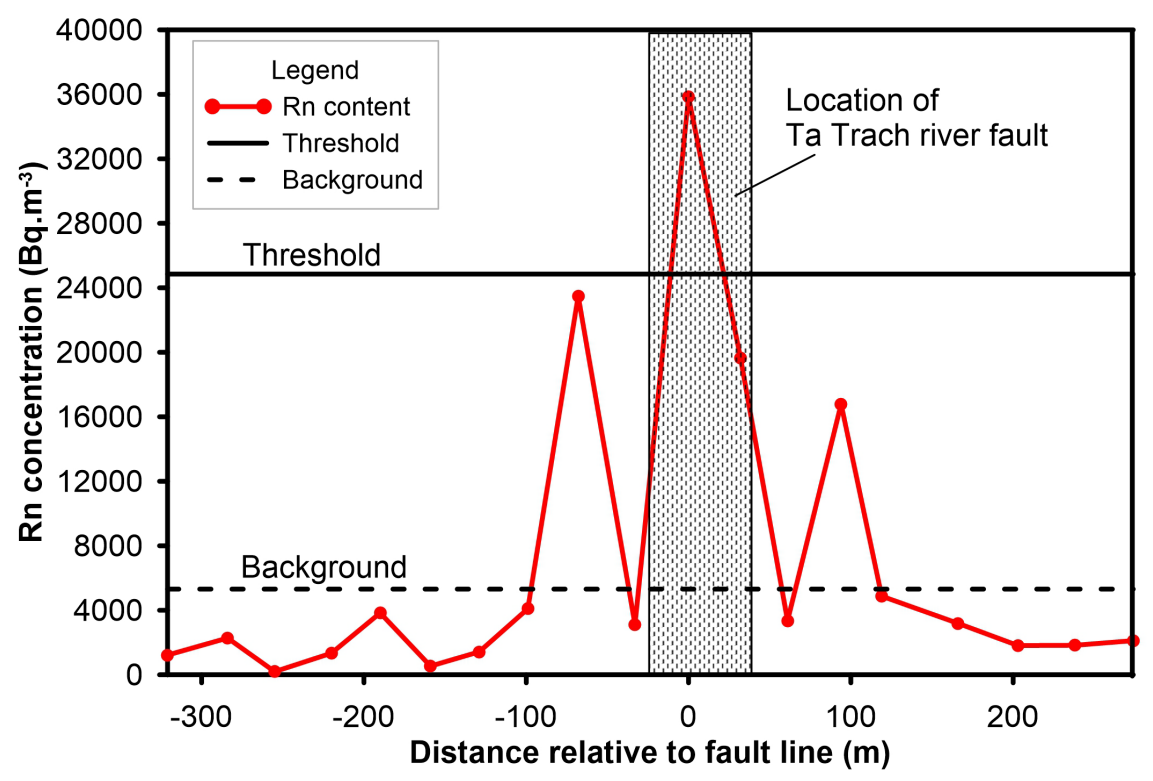

Figure 10. Distribution of soil gas radon concentrations on Ta Trach River fault.

Thus, according to radon measurement results, the activity expression of Song Bo fault is not apparent.

\section{+ High-order Rao Trang fault}

This is a small longitudinal fault that crosses the center of study area and is controlled by the TTH5 measurement profile. No anomaly points were detected on this profile; only the relatively considerable increase in $R n$ concentration was observed at some points adjacent to the fault line, however, the $R n$ concentration was within the range of background values. This indicates that the Rao Trang fault does not show any activity in the present time. 


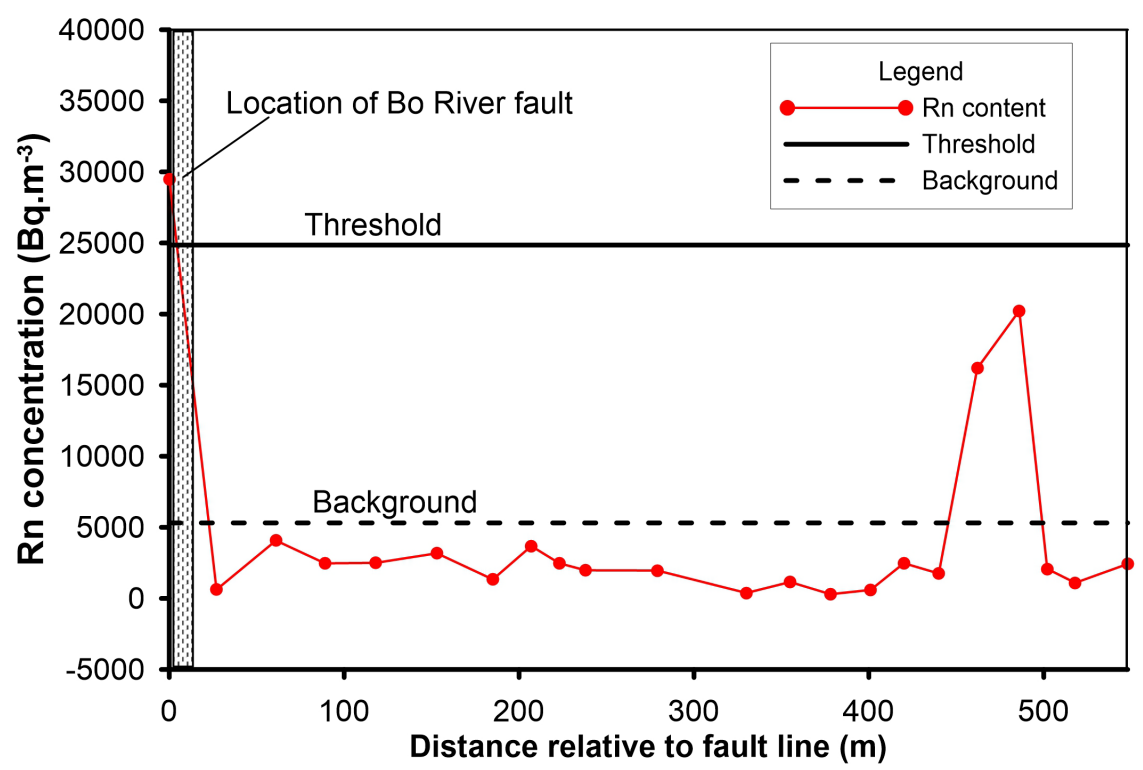

Figure 11. Distribution of soil gas radon concentration on Bo River fault.

It is noteworthy that on all measurement profiles, with or without radon concentration anomalies, the points located above or near the fault line witnessed a relatively considerable increase in soil gas radon concentration compared to the points located further from the fault (not presented here). This demonstrates that the soil gas radon concentration is a strong evidence of the existence of faults or tectonic fracture zones as the radon concentration always increases at the points above or near the fault line.

\section{Conclusion}

In Thua Thien Hue area, the soil gas radon concentration varied widely from $\sim 10 \mathrm{~Bq} / \mathrm{m}^{3}$ to $\sim 145,000 \mathrm{~Bq} / \mathrm{m}^{3}$. Among the rocks present in the study area, the radon background on granite rocks of Dai Loc complex was significantly high and different from that on remaining rocks. The result of measurement profile on granite rocks of Dai Loc complex showed that the radon concentration ranged from $12,460 \pm 259 \mathrm{~Bq} / \mathrm{m}^{3}$ to $133,351 \pm 850 \mathrm{~Bq} / \mathrm{m}^{3}$ with the average value of $37,830 \mathrm{~Bq} / \mathrm{m}^{3}$. The radon background concentration on granite rocks of Dai Loc complex was determined to be $82,849 \mathrm{~Bq} / \mathrm{m}^{3}$. Results of other measurement profiles on remaining rocks indicated that the radon concentration ranged between $\sim 10 \mathrm{~Bq} / \mathrm{m}^{3}$ and $144,570 \mathrm{~Bq} / \mathrm{m}^{3}$, and the average value varied from 4099 $\mathrm{Bq} / \mathrm{m}^{3}$ to $15,694 \mathrm{~Bq} / \mathrm{m}^{3}$. The radon background concentration for these rocks was $24,850 \mathrm{~Bq} / \mathrm{m}^{3}$. Among a total of 245 measurement points, 18 anomaly points of radon concentration were detected.

The activity expression of fault was assessed using radon activity index $K_{R n}$-the ratio of anomaly value to background value of soil gas radon concentration. The assessment results showed that among 18 anomaly points of radon concentration in Thua Thien Hue area, only 01 point had ultrahigh $K_{R n}\left(K_{R n}=27.21\right), 01$ point had high $K_{R n}\left(K_{R n}=18.35\right)$ and 01 point had increased $K_{R n}\left(K_{R n}=11.04\right)$, 
all of which are located on the Dakrong-Hue fault. This demonstrates that in Thua Thien Hue area, only the Dakrong-Hue fault shows a strong expression of activity with high and very high $K_{R n}$. Meanwhile, on the first-order zoned Truong Son fault and its sub-fault, the fourth-order and higher-order faults such as Huu Trach River, Ta Trach River and Bo River faults, some anomaly points were recorded, but $K_{R n}$ was at low and medium levels, indicating that the activity expression of these faults is unclear in the present time. Therefore, in order to clarify the activity expression of all faults, it is necessary to expand the soil gas radon concentration measurement network in the study area.

\section{Acknowledgements}

The authors would like to thank two anonymous reviewers for their helpful comments. This article is the result of the National-level Project "Research and evaluate earthquake hazard for territorial development planning, ensuring safety of hydropower projects, irrigation works and cultural relics in Thua Thien Hue province", code: DTDL.CN.51/16.

\section{Conflicts of Interest}

The authors declare no conflicts of interest regarding the publication of this paper.

\section{References}

(1994). Geological and Mineral Resources Map of Viet Nam on 1:200,000. Ha Noi: Department of Geology and Minerals of Viet Nam.

Al-Hilal, M., \& Al-Ali, A. (2010). The Role of Soil Gas Radon Survey in Exploring Unknown Subsurface Faults at Afamia B dam, Syria. Radiation Measurements, 45, 219-224. https://doi.org/10.1016/j.radmeas.2010.01.018

Barnet, I., Pacherová, P., \& Neznal, M. (2008). Radon in Geological Environment-Czech Experience (pp. 1-50). Praha: Czech Geological Survey, Special Papers.

Baubron, J. C., Rigo, A., \& Toutain, J. P. (2002). Soil Gas Profiles as a Tool to Characterize Active Tectonic Areas: The Jaut Pass Example (Pyrenees, France). Earth and Planetary Science Letters, 196, 69-81. https://doi.org/10.1016/S0012-821X(01)00596-9

Ciotoli, G., Etiope, G., Guerra, M., \& Lombardi, S. (1999). The Detection of Concealed Faults in the Ofanto Basin Using the Correlation between Soil Gas Fracture Surveys. Tectonophysics, 299, 321-332. https://doi.org/10.1016/S0040-1951(98)00220-0

Duong, N. A., Sagiya, T., Kimata, F., To, T. D., Hai, V. Q., Cong, D. C., Binh, N. X., \& Xuyen, N. D. (2013). Contemporary Horizontal Crustal Movement Estimation for Northwestern Vietnam Inferred from Repeated GPS Measurements. Earth Planets Space, 65, 1399-1410. https://doi.org/10.5047/eps.2013.09.010

Duong, T. V., \& Hue, T. T. (1996). Some Results of the Investigation Active Faults in the South Central Viet Nam by Radon Method. Vietnam Journal of Earth Sciences, 18, 276-288. (In Vietnamese)

Font, L., Baixeras, C., Moreno, V., \& Bach, J. (2008). Soil Radon Levels across the Amer Fault. Radiation Measurements, 43, 319-323.

https://doi.org/10.1016/j.radmeas.2008.04.072 
Ghosh, D., Deb, A., \& Sengupta, R. (2009). Anomalous Radon Emission as Precursor of Earthquake. Journal of Applied Geophysics, 69, 67-81. https://doi.org/10.1016/j.jappgeo.2009.06.001

González-Díez, A., Soto, J., Gómez-Arozamena, J., Bonachea, J., Martínez-Díaz, J. J., Cuesta, J. A., Olague, I., Remondo, J., Fernández Maroto, G., \& Díaz de Terán, J. R. (2009). Identification of Latent Faults Using a Radon Test. Geomorphology, 110, 11-19. https://doi.org/10.1016/j.geomorph.2008.12.020

Haerudin, N., Wahyudi, Munadi, S., \& Suryanto, W. (2013). A Soil Gas Radon Survey to Determine Fault at Southern Part of Rajabasa Geothermal Field, Lampung Indonesia. International Journal of Engineering and Technology IJET-IJENS, 13, 75-81.

Hauksson, E. (1981). Radon Content of Groundwater as an Earthquake Precursor: Evaluation of Worldwide Data and Physical Basis. Journal of Geophysical Research, 86, 9397-9410. https://doi.org/10.1029/JB086iB10p09397

Hue, T. T. (1996). First Results of Research Present Geodynamics by Soil Gas Radon Method. In Geology-Resources (pp. 179-185). Ha Noi: Science and Technology Publishing House.

Hue, T. T. (1999). Characteristics of Radon Radioactive Gas in Song Ma Fault Zone. Vietnam Journal of Earth Sciences, 21, 123-128. (In Vietnamese)

Ioannides, K., Papachristodoulou, C., Stamoulis, K., Karamanis, D., Pavlides, S., Chatzipetros, A., \& Karakala, E. (2003). Soil Gas Radon: A Tool for Exploring Active Fault Zones. Applied Radiation and Isotopes, 59, 205-213. https://doi.org/10.1016/S0969-8043(03)00164-7

Kemski, J., Siehl, A., Stegemann, R., \& Valdivia-Manchego, M. (2001). Mapping the Geogenic Radon Potential in Germany. Science of the Total Environment, 272, 217-230. https://doi.org/10.1016/S0048-9697(01)00696-9

King, C. Y. (1978). Radon Emanation on San Andreas Fault. Nature, 271, 516-519. https://doi.org/10.1038/271516a0

King, C. Y., King, B. S., \& Evans, W. C. (1996). Spatial Radon Anomalies on Active Faults in California. Applied Geochemistry, 11, 497-510. https://doi.org/10.1016/0883-2927(96)00003-0

Lacassin, R., Maluski, H., Leloup, P. H., Tapponnier, P., Hinthong, C., Siribhakdi, K., Chuaviroj, S., \& Charoenravat, A. (1997). Tertiary Diachronic Extrusion and Deformation of Western Indochina: Structural and 40Ar/39Ar Evidence from NW Thailand. Journal of Geophysical Research, 102, 10013-10037. https://doi.org/10.1029/96JB03831

Lombardi, S., \& Voltattorni, N. (2010). Rn, He and $\mathrm{CO}_{2}$ Soil Gas Geochemistry for the Study of Active and Inactive Faults. Applied Geochemistry, 25, 1206-1220. https://doi.org/10.1016/j.apgeochem.2010.05.006

Minh, L. H. et al. (2015). Studying Seismic Impacts on the Stability of Song Tranh 2 Dam in Bac Tra My Area, Quang Nam Province. Final Report of the National Project DTDL.2013-G (2013-2016), Hanoi: Institute of Geophysics, Vietnam Academy of Science and Technology. (In Vietnamese)

Morley, C. K. (2004). Nested Strike-Slip Duplexes, and Other Evidence for Late Cretaceous-Palaeogene Transpressional Tectonics before and during India-Eurasia Collision, in Thailand, Myanmar and Malaysia. Journal of the Geological Society, 161, 799-812. https://doi.org/10.1144/0016-764903-124

Moussa, M. M., \& Arabi, A.-G. M. E. (2003). Soil Radon Survey for Tracing Active Fault: A Case Study along Qena-Safaga Road, East Desert, Egypt. Radiation Measurements, 37, 211-216. https://doi.org/10.1016/S1350-4487(03)00039-8 
Nidal, D., Safarini, G., El-hasan, M., \& Iida, T. (2007). CR-39 Detector Compared with Kodalpha Film Type (LR115) in Terms of Radon Concentration. Nuclear Instruments and Methods in Physics Research Section A, 574, 289-291.

https://doi.org/10.1016/j.nima.2007.01.168

Papastefanou, C. (2010). Variation of Radon Flux along Active Fault Zones in Association with Earthquake Occurrence. Radiation Measurements, 45, 943-951. https://doi.org/10.1016/j.radmeas.2010.04.015

Peake, R., \& Schumann, R. (1993). Regional Radon Characterizations. In Field Studies of Radon in Rocks, Soils and Water (pp. 163-174). Florida: U.S. Geological Survey, CRC Press.

Pho, N. V., \& Nga, H. T. (1996). Some Results of the Micro Geodynamic Maping in Thac Ba Area by Using of Nuclear Track Detector Method. In Geology-Resources (pp. 187-191). Ha Noi: Science and Technology Publishing House.

Pho, N. V., \& Yem, N. T. (1996). Gas Geochemical Approach in Study of the Activity of Red River Fault System. Journal of Geology, Ha Noi, Series A, 236, 9-10.

Pho, N. V., Nga, H. T. T., \& Tra, D. T. T. (1999). Study on the Stability of Thac Ba Hydrpopower Dam by Using Nuclear Track Detector Method. Journal of Geology, Ha Noi, Series B, 13-14, 270-271.

Pho, N. V., Nga, H. T. T., Minh, N. T., Tra, D. T. T., Long, V. M., Chung, L. T., Xuyen, N. D., \& Cuong, P. A. (2004). Results of Radon Continuous Measurements in Soil Gas at the North-Western Area. Vietnam Journal of Earth Sciences, 26, 653-656.

Reimann, C., Filzmoser, P., \& Garrett, R. G. (2005). Background and Threshold: Critical Comparison of Methods of Determination. Science of the Total Environment, 346, 1-16. https://doi.org/10.1016/j.scitotenv.2004.11.023

Richon, P., Klinger, Y., Tapponnier, P., Li, C. X., Van Der Woerd, J., \& Perrier, F. (2010). Measuring Radon Flux across Active Faults: Relevance of Excavating and Possibility of Satellite. Radiation Measurements, 45, 211-218.

https://doi.org/10.1016/j.radmeas.2010.01.019

Seminsky, K. Zh., \& Demberel, S. (2013). The First Estimations of Soil-Radon Activity near Faults in Central Mongolia. Radiation Measurements, 49, 19-34.

https://doi.org/10.1016/j.radmeas.2012.12.013

Tapponnier, P., Peltzer, P., Le Dain, A. Y., Armijo, R., \& Cobbold, P. (1982). Propagating Extrusion Tectonics in Asia: New Insights from Simple Experiments with Plasticine. Geology, 10, 611-616. https://doi.org/10.1130/0091-7613(1982)10<611:PETIAN >2.0.CO;2

Tuc, N. D. (2000). Kinematic Characteristics of the Red River-Chay River Fault Zone in Cenozoic. Vietnam Journal of Earth Sciences, 22, 174-180. (In Vietnamese)

Tung, S., Leung, J. K. C., Jiao, J. J., Wiegand, J., \& Wartenberg, W. (2013). Assessment of Soil Radon Potential in Hong Kong, China, Using a 10-Point Evaluation System. Environmental Earth Sciences, 68, 679-689. https://doi.org/10.1007/s12665-012-1782-0

Utkin, V. I., \& Yurkov, A. K. (2010). Radon as a Tracer of Tectonic Movements. Russian Geology and Geophysics, 51, 220-227. https://doi.org/10.1016/j.rgg.2009.12.022

Wakita, H., Nakamura, Y., Notsu, K., Noguchi, M., \& Asada, T. (1980). Radon Anomaly: A Possible Precursor of the 1978 Izu-Oshimakinkai Earthquake. Science, 207, 882-883. https://doi.org/10.1126/science.207.4433.882

Walia, V., Mahajan, S., Kumar, A., Singh, S., Singh, B., Dhar, S., \& Yang, T. F. (2008). Fault Delineation Study Using Soil-Gas Method in the Dharamsala Area, NW Himalayas, India. Radiation Measurements, 43, 337-342. 
https://doi.org/10.1016/j.radmeas.2008.04.071

Wang, X., Li, Y., Du, J., \& Zhou, X. (2014). Correlations between Radon in Soil Gas and the Activity of Seismogenic Faults in the Tangshan Area, North China. Radiation Measurements, 60, 8-14. https://doi.org/10.1016/j.radmeas.2013.11.001

Xuan, P. T., Pho, N. V., Chinh, V. V., Dang, P. T., Lien, N. T., Tra, D. T., Nga, H. T., Quynh, B. V., Luan, N. V., \& Qua, N. X. (2017). Study on Active Tectonic Faults Using Soil Gas Radon Method in Viet Nam. Vietnam Journal of Earth Sciences, 39, 27-46. https://doi.org/10.15625/0866-7187/39/1/9182

Xuyen, N. D. et al. (2004). Study on Earthquake Prediction and Ground Motion in Vietnam. Final Report of the National Project 2000-2002, Hanoi: Institute of Geophysics, Vietnam Academy of Science and Technology. (In Vietnamese)

Yem, N. T. (1996). Regimes of Tectonic Stress Field during Cenozoic in Vietnam. Journal of Geology, Ha Noi, Series A, 236, 1-6. (In Vietnamese)

Yin, A. (2010). Cenozoic Tectonic Evolution of Asia: A Preliminary Synthesis. Tectonophysics, 488, 293-325. https://doi.org/10.1016/j.tecto.2009.06.002 